\title{
NUEVAS VIRTUALIDADES EN LA ENSEÑANZA DE LENGUA Y LITERATURA
}

Jhonattan Andrés Benavides Jurado 


\section{NEW VIRTUALITIES IN THE TEACHING OF LANGUAGE AND LITERATURE}

RESUMEN

El temor ante el avance acelerado de las nuevas tecnologías de la información y la comunicación no constituye una novedad psicofisiológica en la historia técnica o emocional del homo communicans, ni la virtualidad ha representado su descubrimiento más insubordinado. Antes bien, el arte escrito ha sido, milenariamente, el medio privilegiado del dominio humano sobre la virtualidad y, sin lugar a dudas, la herramienta predilecta de enseñanza de las lenguas. Una reflexión más serena y un memorial objetivo de su papel en la historia universal podrán despertar la fe en la mediación de las nuevas virtualidades para la enseñanza de Lengua y Literatura.

Palabras clave: virtualidad, literatura, idioma, comunicación, pedagogía.

\section{ABSTRACT}

Fear of the accelerated advance of new information and communication technologies is not a psychophysiological novelty in the technical or emotional history of homo communicans and the virtuality has not represented its most insubordinate discovery. On the contrary, written art has been, for millennia, the privileged medium of human domination over virtuality and, without a doubt, the preferred tool of language teaching. A calmer reflection and strict remembrance of its role in universal history will awake faith in the mediation of new virtualities for the teaching of language and literature.

Keywords: virtuality, literature, language, communication, pedagogy.

\section{AUTOR}

Jhonattan Andrés Benavides Jurado

Maestría en Formación y Perfeccionamiento del Profesorado en Lengua y Literatura de la Universidad de Salamanca.

Estudiante del programa de Literatura virtual de la Universidad Autónoma de Bucaramanga 


\section{INTERNET, UN NUEVO CONTINENTE}

\subsection{Aproximación a la antropología de la comunicación}

En el año 2012, Luis Duch y Albert Chillón publicaron el primer volumen de la obra Antropología de la comunicación. Pasaron cerca de cuatro años antes de que se publicara el segundo volumen, titulado Sociedad mediática y totalismo. Más allá del dato histórico de esta investigación, conviene decir que se trata de un trabajo realmente juicioso sobre el insustituible lugar de las mediaciones en las realidades humanas y sobre su protagonismo en el establecimiento progresivo de una cultura mediática "que ha devenido hegemónica y planetaria" (Duch y Chillón, 2016, p. 11).

Sus conclusiones no solo interpelan al conjunto de las ciencias sociales y a las humanidades sobre la necesidad de actualizar la teoría de la comunicación, sino que se constituyen en una novedosa propuesta antropológica. A partir de ella podría hablarse de un nuevo hombre, ya no solamente racional, social, sensible (capaz de afecto), religioso, sino comunicante (homo communicans) y, más aún, "conformado y modulado por las mediaciones que el «sistema tecnodigital» propulsa" (Duch y Chillón, 2016, p. 12).

A decir verdad, no es que la suya resulte ser una obra definitiva sobre el ser humano; pero, sin lugar a dudas, aborda cuestiones que, como es natural en el proceso evolutivo de las ciencias, ignoramos o evadimos porque suelen parecernos un conjunto más de asuntos que desestabilizan los paradigmas existentes y que no traen consigo más que problemas de los que parece mejor tomar distancia. Sin embargo, cabe decir que para Duch y Chillón (2012) es precisamente la situación del hombre actual, inmerso en la era de la información, la que ha permitido que las principales cuestiones de su obra salgan a flote y que el carácter de las mediaciones en la realidad humana haya cautivado su interés investigativo para volver a las preguntas esenciales sobre el anthropos

Así, estos autores precisan que:

Los actuales media, tan variados, flexibles y ambiguos, son indispensables para renovar el gran interrogante antropológico de todos los tiempos - ¿qué es el ser humano? -, imposible de responder de una vez por todas. En este asendereado arranque del siglo XXI, la antropología de la comunicación está llamada a ser la antropología a secas, no en única pero sí en relevante medida. (p. 55)

Mucho se ha elogiado esta obra y parece que ya es justo que las presentes páginas dejen de parecer una reseña para considerar ciertos tópicos que son vértebras de esta columna temática. El primero de ellos alude a la necesidad del ser humano de acortar la distancia entre sí mismo y su entorno, valiéndose de su propio cuerpo y de otras tantas mediaciones que encuentra fuera de él.

Tal argumento puede ser ilustrado por realidades que nos circundan, que experimentamos en primera persona o que han llegado a ser hitos de la historia reciente de las comunicaciones. Basta recordar -si es que no se conoce la historia de primera mano- el film de Fincher (2010), The social network, que narra los orígenes de Facebook. Este comienza con una escena en la que el protagonista (Mark Zuckerberg, interpretado por Jesse Eisenberg) fracasa en su intento de suscitar espacios de comunicación asertiva con una joven.

Parece osado el solo hecho de pensarlo, pero es precisamente este fracaso comunicativo el que desembocó en la creación de uno de los fenómenos sociales más estudiados en la actualidad: Facebook. El boom generado por esta y otras redes digitales afi- 
nes es quizás una de las pruebas más latentes de la urgencia que experimenta el ser humano de acertar en el uso de mediaciones que le permitan resolver las ausencias y las distancias, tal como lo explicitan Duch y Chillón (2012):

La comunicación es inmanente al anthropos porque este se halla siempre alejado de los otros, del entorno, y de sí mismo; de ahí que se sienta urgido a resolver el perentorio e imposible afán que le impone su extrañeza. Los procesos comunicativos son ensayos de aproximación, esfuerzos por salvar disgregaciones y ausencias, distancias físicas y mentales (p. 33).

Lo anterior no solo se deduce de hechos surgidos tras la aparición de las nuevas tecnologías de la información, sino que es posible leerlo en el establecimiento de los más rudimentarios sistemas alfabéticos y, mucho antes de su aparición, en remotas fuentes arqueológicas que hablan de las primeras civilizaciones. Tal como lo relata el primer libro de la Torá judía y otros tantos textos asociados a extintas religiones mistéricas, el ser humano halló la manera de establecer relaciones con su entorno, con los demás seres de su especie e incluso con deidades que, de acuerdo como lo relatan las tradiciones, tampoco escatimaron medios para atraer la atención de sus criaturas. A este respecto, conviene recordar algunos diálogos que se dan entre Yahvé -que sale al encuentro del hombre- y este último, que no consigue eludirlo (Gn 3,8-10; 4,9-10).

Queda claro que al hablar de una determinada práctica comunicativa debe aparecer, en el mismo plano, la alusión a las técnicas que median para que ocurra. Entre estas últimas, las más primitivas son esos rudimentarios intentos de escritura que hablan con firmeza del valor de la comunicación para el establecimiento de una cultura y, con ella, para el nacimiento de una civilización.
Al menos desde la invención de la escritura -una versátil tekhné de fijación del recuerdo, no se olvide-, sucesivas técnicas y procederes han ido ahormando no solo la expresión, transmisión y recepción de la cultura, en su acepción estricta, sino la misma civilización en sentido amplio. (Duch y Chillón, 2012, p. 14)

¿Cuál es la tekhné que está a la base de nuestra civilización, de esta nueva era? Siguiendo los planteamientos ya expuestos, es precisamente la amplia red de comunicaciones que se ha denominado Internet. Y aunque en pedagogía se ha venido hablando de la civilización del conocimiento -que tiene como materia prima la neurona- resulta más cercano a la realidad y a su devenir hacer referencia a una civilización digital que tiene como materia prima la información y como herramienta el ordenador, tal como lo refiere Dahlgren (2012):

La digitalización es, sin ningún género de dudas, la mayor tendencia tecnológica de los medios en la actualidad; las últimas dos décadas han presenciado una profunda transformación tecnológica de los medios que continúa acelerándose. Dicho de forma simple, está surgiendo un lenguaje electrónico común, basado en los "bits" del ordenador, para toda comunicación mediatizada (p. 193).

Esta era -no época, como parecía que se denominaría a finales del siglo pasado (Duch y Chillón, 2016) - que se ha venido gestando desde la modernidad, tal como lo reconocen Ciofalo y Leonzi (2013) "La modernità è lo scenario in cui si sviluppa compiutamente la comunicazione, così come noi oggi la conosciamo" ( $p$. 125), es la era por excelencia del ser de mediaciones al que denominamos homo comunicans, tan necesitado de romper disgregaciones, ausencias y distancias, 
tanto físicas como mentales. Es esta nueva visión del hombre -en clave de mediación- la que interpela a las ciencias humanas y -con no menor fuerza- a las didácticas, tan ocupadas en profundizar en los procesos de enseñanza-aprendizaje que dan lugar a nuevos hombres en nuevas sociedades.

\subsection{El nuevo continente digital, ¿metáfora o realidad?}

Fue apenas en la década de los 90 cuando comenzó a descubrirse, con lentos artilugios informáticos, un mundo de infinitas posibilidades: el mundo de Internet. Un par de años más tarde nadie sabía a ciencia cierta si la humanidad se encontraba ante una isla o un continente, parafraseando a Robinson Crusoe, personaje creado por Daniel Defoe. Empero, investigaciones como la publicada por De La Cueva (2001), en la misma web, bastaron para que este nuevo escenario pasara a adquirir convenientemente la categoría de continente, planeta y universo. Aunque tal estudio está desactualizado a nivel de datos estadísticos, el artículo que lo acompaña otorga una visión general de lo que significa la atribución de estas categorías a Internet. Su autor aborda la realidad de este nuevo «espacio geográfico» con cifras que ya en el año de su composición provocaron una alarma generalizada que advertía la mutación de un sinnúmero de experiencias humanas de mediación:

El ciberespacio, Internet, es ciertamente un Nuevo Continente. Su ocupación apenas ha comenzado y avanza aceleradamente. $Y$ ya tiene dimensiones gigantescas. El "mundo" web de Internet es el fenómeno tecnológico de masas más espectacular de toda la Historia. Aún más, sociológicamente hablando es el fenómeno de masas "concreto" no bélico de más rápido crecimiento de la historia. (De La Cueva, 2001)
El uso de dicha categoría, resultante de la comparación entre el índice poblacional de los continentes existentes y el número de usuarios de Internet, permite constatar que la web se ha convertido en realidad ineludible para una gran parte de seres humanos en el mundo y que su uso sigue creciendo inusitadamente hasta confirmarse que la mayoría de los habitantes del planeta tienen que ver, directa o indirectamente, con esta nueva composición geográfica virtual.

Tal como ocurre en otros ámbitos de estudio, el uso de la expresión "continente digital» puede haber nacido como una metáfora para advertir la complejidad de las realidades que en torno a la web se entretejían; sin embargo, esta dejó de ser una mera figura literaria desde que las estadísticas comenzaron a develar el promedio de tiempo que invierte un adulto joven revisando su teléfono inteligente o desde que algunas organizaciones como la World Wide Web Foundation se dieron a la tarea de renovar datos, minuto a minuto, del número real de usuarios en Internet:

The number of internet users has increased tenfold from 1999 to 2013. The first billion was reached in 2005 . The second billion in 2010. The third billion in 2014. The chart and table below show the number of global internet users per year since 1993. (International Telecommunication Union y United Nations Population Division, 2014, párr. 2)

Más recientemente, en el Internet Trends Report 2017 -el resumen más influyente del estado de Internet y tendencias en el mundo de la comunicaciónMary Meeker, develó que el acceso a Internet crece un $10 \%$ al año. No cabe duda, tras leer estos datos, de que Internet es un verdadero lugar de encuentro en el que confluye una gran cantidad de hombres y mujeres de todas las edades. Si tal espacio permite establecer nuevas cartografías, su comparación con los continentes que aparecen en el mapamundi no es 
ya un símil o una hipérbole, y no será descabellado descubrir en él nuevas mediaciones; esto es, nuevas personas ocupadas en la tarea, como ya fue señalado anteriormente, de gestar nuevas relaciones.

\subsection{Nuevas geografías, nuevas relaciones y nue- vos hombres}

Ciertamente, el número de usuarios de Internet nos devela la magnitud del espacio geográfico virtual que se ha ido gestando. No obstante, vale decir que no fue exclusivamente el número de habitantes lo que permitió a Europa asumir a América como un nuevo continente. Más que la densidad poblacional, fueron las características del territorio inexplorado, hasta entonces, las que posibilitaron el uso de la misma categoría geográfica que hoy por hoy la Organización de las Naciones Unidas (ONU) usa para dar nombre a las cinco partes de tierra más extensas y culturalmente más próximas de la tierra. En dicho espacio se comprobó la existencia de una civilización (o de varias, si se tiene en cuenta que algunas se encontraban en un estadio diverso de desarrollo), con rasgos sociopolíticos, culturales y religiosos concretos.

En este orden de ideas, no cabe más que afirmar que Internet es, a la vez, mediación y espacio geográfico. Por ser mediación se constituye en el elemento primordial para interpretar la sociedad digital. Esto es, el tipo de relaciones entre emisores y receptores que usan la web como medio para transmitir un mensaje; por ser espacio, es condición esencial para la gestación de nuevas mediaciones que surgen del encuentro de quienes lo habitan.

Por ende, puesto que Internet es a la vez espacio y mediación - pero no actor de la comunicación, pues ni es emisor ni es receptor o perceptor- ¿de dónde procede el desarrollo de sus propiedades? Tal como lo reconoce Zanoni (2008), en esta civilización establecida en el continente digital, el protagonista sigue siendo el hombre y -en términos de navegación- el usuario, quien ya no solo recibe información, sino que contribuye a la caracterización de su papel en la red y a la arquitectura de su entorno virtual:

Desde hace algunos años, el protagonista absoluto de Internet es el usuario. Vos y yo. Somos nosotros quienes producimos y consumimos contenidos (textos, fotos, audios, videos, links, etc.) y quienes nos unimos con otras personas para compartir información o para hacer nuevos amigos (p. 21).

En efecto, hace solo algunos años cabía pensar que el motor de la red eran los contenidos; es decir, la información que por su medio se compartía. El simple hecho de recordar la razón por la cual Internet existe nos obligaba a pensar que eran los datos los protagonistas de su evolución. Únicamente de este modo podía comprenderse por qué a mayor cantidad de datos, más acelerado se tornaba el crecimiento de la red.

Sin embargo, los datos pasaron a un segundo plano cuando el individuo -o usuario, como ya lo hemos llamado- llegó a constituirse en el banco informativo de la red y tal papel dejó de ser ejercido únicamente por organizaciones y Estados. De modo que los contenidos que circulan en Internet no son ya únicamente información codificada en mapas de bits, sino verdaderas dinámicas

sociológicas que, aunque pueden traducirse en términos aritméticos mediante la estadística, no están compuestas por bibliotecas informáticas que dan cuenta, por ejemplo, de estrategias de guerra, sino por los frutos de las relaciones entre usuarios que han ido conformando una civilización con un espacio geográfico virtual propio.

A este respecto resulta iluminadora la posición de Spadaro (2012), quien ha conseguido dilucidar al- 
gunas de las problemáticas esenciales sobre una nueva sociedad que habita el espacio digital:

La società digitale non é più pensabile $\mathrm{e}$ comprensibile solamente attraverso i contenuti, ma soprattuto attraverso le relazioni e lo scambio dei contenuti che avviene all'interno delle relazioni tra persone. La base relazionale della conoscenza in rete è radicale. Infatti, grazie alla lógica dei link ogni contenuto può essere messo in direta relazione con altri contenuti della rete, dovunque essi siano depositati (p. 69).

De modo que, si la sociedad digital es comprensible a través de las relaciones que en ella se establecen, es necesario caracterizarlas con el fin de, a su vez, fijar una idea de lo que significa para nuestro momento histórico la aparición de un nuevo continente. No obstante, más allá de poder hablar de un tipo único de relaciones, conviene reconocer con Sanabria (2011) que el mundo virtual es un abismo entre proximidad y lejanía en el que se construye una pluralidad de sentidos y en el que no cabe la idea del deber ser. Más aún, tal como lo afirman Duch y ChiIlón (2016), "el caudal de prácticas, estilos y productos que la mediosfera incluye es tan ingente, y tan vertiginosas sus mutaciones a lomos de la tecnología digital, que no hay mente capaz de dar cuenta de él con suficiente completud y profundidad" (p. 11).

En otras palabras, la multiplicidad de sentidos y la imposibilidad de establecer prototipos mediante una deontología, nos obliga a pensar en la pluralidad de relaciones que pueden establecerse en este nuevo espacio digital. No es esta una evasiva para huirle a la caracterización; puesto que, si de definir se tratara, podría acudirse a visiones pesimistas de estas nuevas relaciones o hablar, desde la esperan$z a$, de un escenario de encuentro y detenerse en una visión del ya activo continente digital que, bien sea optimista o pesimista, no deja de ser un osado acercamiento a relaciones que en cuanto se definen ya han mutado con el surgimiento de nuevas mediaciones. A esta idea de una estructura que se alimenta de relaciones y cuya arquitectura potencia el intercambio, Cobo y Pardo (2007) la describen del modo que aparece a continuación:

La estructura tecnológica se expande de manera conjunta con las interacciones sociales de los sujetos que utilizan Internet. Bajo esta idea, cada vez que una persona crea un nuevo enlace la Red se complejiza $y$, por tanto, se enriquece. La idea de una arquitectura de la participación se basa en el principio de que las nuevas tecnologías potencian el intercambio y la colaboración entre los usuarios (p. 49).

De modo que podríamos limitarnos a referir, con Malini (2013), que Internet es un espacio en el que confluyen relaciones que divagan entre lo real y lo virtual (entre proximidad y lejanía) y en el que múltiples voces se van adecuando a la mutación de la mediación. Su visión, aunque política por la naturaleza de su estudio, revela cómo este encuentro entre realidad y virtualidad propicia una interacción solidaria entre heterogeneidades.

No espaço dialógico da realidade virtual da Internet, a sociedade se revelaria "um corpo multivozes metamorfoseando-se", implicando para a democracia, real ou virtual, a necessidade de sustentar a interação ou a solidariedade das "vozes" do seu corpo e, ao mesmo tempo, de respeitar sua heterogeneidade (p. 78).

Por otro lado, si fuera menester una ejemplificación de lo ya dicho, tal como se hizo en un apartado anterior, conviene acudir a uno de los trabajos ci- 
nematográficos de Jonze (2013) que evidencia los más sorprendentes matices que puede tomar una relación gestada desde lo virtual. Her es un film futurista ambientado en Los Ángeles que narra el drama amoroso entre Theodore Twombly (interpretado por Joaquin Phoenix) y un avanzado sistema operativo inteligente, sensible y hasta simpático.

Más allá de describir el tipo de relaciones que surgirán en un futuro cercano, Jonze nos permite acercarnos a una situación que ya es visible a la vuelta de la esquina: hombres y mujeres que dependen de mediaciones electrónicas para establecer vínculos y cuyas relaciones, en algunos casos, se reducen al trato con sus dispositivos electrónicos, bien sean computadoras, teléfonos móviles o lentes que permiten no solo ver un entorno sino fotografiarlo y almacenar dichas tomas en un disco duro o en la misma nube.

Es quizás en personas que encarnan al protagonista ficticio de Jonze, Theodore Twombly, en quienes las paradojas del homo communicans, precisadas por Ciofalo y Leonzi (2013), toman cuerpo. El hombre que se define por sus mediaciones es un hombre nuevo que solo pudo haber surgido en un espacio en el que la mediación determina la relación del ser humano consigo mismo, con su entorno y con los demás seres de su especie.

L'homo comunicans, dunque, riassume in sé lo slancio verso l'innovazione e la resistenza nei confronti del cambiamento, la ricchezza delle tante occasioni di interazione e relazione e la paura della solitudine, la crescente necessità di essere continuamente connesso e l'ossessione di non riuscirci, l'aspirazione alla libertà e alla individualità e a la schiavitù nei confronti del consumo, delle mode e della frenesia comunicativa (Ciofalo y Leonzi, 2013, p. 137).
Por tanto, si hemos reconocido que existe una nueva cartografía en la que debería aparecer un continente transversal, donde confluyen personas de diversas latitudes, también debemos reconocer la gestación, en tal entorno, de nuevas relaciones. Estas últimas han cobrado tanta importancia que no son ya meros datos los que determinan el crecimiento de la web sino la aparición de nuevas mediaciones usadas por seres cuyas paradojas se agudizan en entornos digitales, como las populares redes sociales.

\section{LA METAMORFOSIS DE LO REAL}

"Tras abrir los ojos, se vio a sí mismo convertido en un insecto". Esta no es una frase tomada del libro Die Verwandlung de Franz Kafka, aunque así parece; es el comienzo del relato, en tercera persona, de la primera experiencia con HMD (head-mounted display) de un jugón. Sin lugar a dudas, el relator ignoraba que sus palabras ya habían sido escritas antes y que constituían una de las sentencias más reconocidas de la literatura alemana. Estamos ante un hecho real que ya fue tal en 1915, cuando salió a la luz la publicación kafkiana. Ahora bien, ¿qué es aquello que lo hace más real en la actualidad que entonces?; ¿qué lo hace más virtual ahora que si llegara a darse en un entorno no concebido hasta hoy?

No hace falta, para el fin que justifica estas páginas, establecer niveles de realidad a fin de responder las preguntas precedentes; basta reconocer algunas de las múltiples formas que esta puede tomar y que ha tomado desde mucho antes de que Jaron Lanier hablara de realidad virtual o de que el doctor angélico usara el término virtualis para referirse a aquello "que tiene la capacidad de funcionar como algo aunque realmente -o «actualmente», dirían Santo Tomás o Aristóteles- no lo sea, algo que sin ser real produce el mismo efecto que si lo fuera" (Biosca, 2009, p. 35). 
Bien es sabido, por ejemplo, que Homero no es el padre de la historiografía occidental y que La Odisea no constituye un relato histórico, en los términos en los que actualmente definimos la historia. No obstante, el rasgo de irrealidad que excluye esta obra homérica del cúmulo de libros que encabeza la Historiae de Heródoto no fue impedimento para que fuera leída por los griegos como la mismísima memoria de Grecia. Más aún, muy por encima de la recurrencia a la imaginación, la obra continúa siendo hasta el presente una fuente de información veraz sobre cuestiones que serían incognoscibles sin el mito o la Arqueología.

Este es solo un ejemplo de la literatura clásica, que ilustra cómo los avances en materia de realidad virtual y las reflexiones por ella suscitadas han provocado el distanciamiento de la concesión definitiva del atributo de irreal a una cosa por el mero hecho de haber sido concebida en el cerebro humano antes de cosificarse y hacerse sensorial. Al ejemplo homérico podríamos sumar otros testimonios literarios que evidencian cómo mucho antes de que la virtualidad interpelara a las ciencias humanas y sociales, la realidad se había metamorfoseado gracias al poder ejercido por la literatura en los lectores. No obstante, de forma paradójica, en medios académicos y artísticos pervive la subestimación de todo cuanto se encuentre mediado por las tecnologías de la información y la comunicación - distractores virtuales o digitales-, mientras se mantiene vivo el poder del papel como único mediador capaz de traer a la existencia toda forma de razonamiento o arte escrito.

A pesar de lo dicho, resulta innecesario retornar a la discusión sobre aquello que realmente es arte, a fin de no deambular hasta caer en un laberinto. Empero, viene bien anotar que la sola duda sobre cuánto se considera real daría lugar a un nuevo capítulo en dicho debate. $Y$ si el anterior vericueto resulta innecesario, aquello que exige una revisión atenta es cómo la realidad misma, tal como lo reconocen Duch y Chillón (2012), puede constituir una hoja en blanco a merced de aquel que la afronta:

La psiqué no es una tábula rasa en la que presuntamente se imprimirían, por decirlo así, las sensaciones inducidas por los estímulos externos, una suerte de emulsión virgen que tomaría la forma de lo recibido de forma pasiva. Sucede, de hecho, que es ella la que activamente, gracias a la imaginación, muta el trato sensorial con «lo real» [...] «Lo real» es, como tal, enigmático e incognoscible en última instancia, eso que existe con independencia de los designios del anthropos y se opone a ellos; hasta tal punto que, enfrentado a "ello» sin cesar, este tiende a construir un mundus a su semejanza e imagen, uno o diversos orbes imaginarios que preña de sentido y en los que su nudo "existir» deviene «vida» en sentido estricto (p. 236).

Considerado este postulado, la metamorfosis de lo real no es una mera metáfora que da cuentas de las múltiples facetas que puede asumir un hecho en el ámbito narrativo, sino que es la expresión más cercana a la manifestación de lo real. Así pues, aquella máscara que asume el anthropos, denominada personalidad (palabra de origen griego), equivaldría guardadas las proporciones- a las manifestaciones de la realidad; esto es, a sus formas cambiantes.

Ya en el siglo IV de nuestra era, nos fue legado un ejemplo fehaciente del poder ejercido por la narrativa en la realidad. En el primero de los libros de sus Confessionum -obra que devela una lucidez psicológica poco común para la época-, Agustín de Hipona relata el resultado de un ejercicio de introspección que le permite poner en entredicho su actuación frente a la literatura: 
Quid enim miserius misero non miserante se ipsum et flente Didonis mortem, quae fiebat amando Aenean, non flente autem mortem suam, quae fiebat non amando te, Deus, lumen cordis mei et panis oris intus animae meae et virtus maritans mentem meam et sinum cogitationis meae?

De inmediato, se advierte que el lamento de Agustín, en forma de pregunta, no tiene un fin estético sino analítico: poner en entredicho el nivel de afectación que generaron, durante su estudio de Gramática y Retórica, las narraciones clásicas. El mismo juicio que efectuamos en contra de la realidad virtual hoy, lo abrió en su tiempo Agustín para judicializar la narración sobre el suicidio de Dido por amor a Eneas: ¿cómo es que un hecho que carece de existencia actual puede provocar las mismas emociones que podría generar si abandonara su capacidad de ser (virtualidad) para ser actualmente?

Puede que los testimonios más antiguos de las relaciones entre lectores y textos nos conduzcan hasta los primeros vestigios arqueológicos de la humanidad, de modo que remontarse a la prehistoria de la virtualidad exigiría el paso a través de la narración escrita y de las tradiciones orales de las comunidades más antiguas. Incluso la más versátil tekhné de fijación del recuerdo, como ya lo mencionamos en el primero de los apartados, debió permitirle a la realidad asumir ciertos estados de transgresión de estereotipos socialmente aceptados. Razón tienen, en este sentido, Duch y Chillón (2012) al afirmar que:

El relato comparte con el arte, la poesía, la religión y el mito la aptitud de trascender el simple entendimiento -el espirit géométrique que Pascal asignaba a las ciencias naturales y exactas- para alcanzar el espirit de finesse: una "comprensión» (Versehen) de tenor cualitativo que requiere el simultáneo juego de logos y mythos, concepto e imagen, efectividad y afectividad, análisis y síntesis: de razón y sensibilidad, en suma" (p. 296).

A modo de apéndice de este apartado, además de lo ya mencionado, cabe decir que el texto del hiponense revela el papel que desde la antigüedad desempeñaba la literatura en la enseñanza de idiomas. No cabe duda que la narrativa, vinculada estrechamente a la escuela, bien sea como sierva de esta o como compañera, ha sido el escenario de encuentro de un número impensable de experiencias humanas de formación.

\section{EL MAESTRO DE LENGUA Y LITERATURA EN TIEMPOS DE PANMEDIACIÓN Y TOTALISMO}

Ciertamente, como se ha dicho en reiteradas ocasiones, Internet es, hoy por hoy, una realidad ineludible para la educación. Su acelerado crecimiento ha llegado a valerle la calificación de continente digital, en términos de virtualidad, y progresivamente ha ido exigiendo nuevas formas de situarse frente a la realidad. "La crescita esponenziale e inarrestabile del web, ossia la Rete di internet, ha provocato una modificazione degli stili di vita, dei processi di construzione della conoscenza, delle stesse necessità e aspettative dell'umanità odierna" (Riccieri, 2011, p. 13).

A esta capacidad de abarcar todas las realidades humanas y a la necesidad del anthropos de ser, exclusivamente a través de las mediaciones, la denominamos panmediación. A modo ilustrativo, convendría recordar el ingenioso filme que dirigió en 2014 Wally Pfister; este relata los esfuerzos que Will Caster (interpretado por Johnny Depp) invierte en la creación de una máquina con conciencia colectiva y autosuficiente. Las consecuencias de su ingenioso proyecto resultan devastadoras para cualquier ciudadano del siglo $\mathrm{XXI}$, a pesar de que este ya ha comenzado a experimentar situaciones que, vistas a 
través de una pantalla, parece que hacen parte de un ingenioso libreto de ciencia ficción.

Estas realidades han dejado de pertenecer al dominio de lo imaginario y lo utópico y están exigiendo indagar sobre la posibilidad de concebir un humanismo sin hombre (Finkielkraut, 2006); es decir, si Internet ha resultado ser la culminación y no una mera etapa del progreso técnico para que, por primera vez, nos estemos viendo abocados a concebir un ser capaz de construirse a sí mismo a través de las mediaciones que abarcan todas sus realidades.

Continuando con una lectura del argumento de Transcendece no solo podríamos evidenciar los peligros que nacen de la idea de un ser humano que se construye a sí mismo, sino que, gracias al dominio de la información, terminaría adquiriendo el estatus de conciencia colectiva y obteniendo el control cosmológico total. El final de la cinta sugiere que esta realidad no sería tan caótica como beneficiosa para el universo y concretamente para el ser humano. Sin embargo, tal como se pregunta Finkielkraut (2006), iestaremos realmente preparados para asumir la utopía de un mundo ordenado por una inteligencia superior?

¿Quién de nosotros desearía realmente vivir en la ciudad ideal o en ese mejor de los mundos donde la imperfección de las leyes humanas cedería ante el rigor de las leyes naturales, donde el desorden del debate retrocedería frente al orden de los procesos técnicos? (p. 51).

No estamos tan lejos, de acuerdo con Duch y Chillón (2016), de experimentar el dominio de las mediaciones. Más aún, ellos ya le han dado el nombre de totalismo (redefinición del totalitarismo) y, aunque no se lo atribuyen a una conciencia artificial superior, se lo otorgan a los actuales poderes instituidos que se valen de las mediaciones para ejercer su dominio:
"Empalabramientos, iconismos y liturgias conforman la triada discursiva que todo poder convoca, a fin de ahormar, las mentalidades de sus partícipes, cómplices y súbditos" (p. 209).

\subsection{Comunión entre virtualidades}

Recientemente, la Biblioteca Nacional y el Ministerio de Cultura de Colombia, bajo el lema "Lee lo que quieras, pero lee", lanzaron una iniciativa para ampliar el concepto de lectura y promover hábitos en torno suyo, según lo manifiestan en su sitio web, sin prestar mayor interés a la mediación a la que se acceda para lograrlo. Sin ir más allá de lo que se puede ver a simple vista, esta es una de las tantas evidencias de que Internet está pasando de ser el simple banco de datos, al cual se accedía para extraer información codificada, a convertirse en un espacio afable de encuentro real y creativo entre el usuario y los contextos que ofrece la virtualidad.

La multiplicidad de experiencias que pueden brotar de cada encuentro en este continente es tan abierta $y$, paradójicamente, susceptible de categorización que podríamos atribuirle las mismas palabras que Borges (2009) usó alguna vez para referirse a la Biblioteca de Babel: "Si un eterno viajero la atravesara en cualquier dirección, comprobaría al cabo de los siglos que los mismos volúmenes se repiten en el mismo desorden (que, repetido, sería un orden: el Orden)" (p. 866).

Esta infinitud (de relaciones y formas de ser) que ofrece el nuevo continente abre las posibilidades de acción, no solo al afanado buscador de pasatiempos sino al curioso investigador o al inquieto aprendiz. En este sentido, las tecnologías de la información y la comunicación ya no constituyen una mera autopista de acceso para el usuario, sino que, tal como lo describen Monereo y Coll (2008), han pasado a ser un laboratorio que podría colmar su tiempo escolar: 
La exigencia de que las TIC estén presentes en las escuelas no plantea pues duda alguna. La cuestión es más bien, como señala BRUNNER (2000), la extensión y el sentido de esta presencia. No es lo mismo considerarlas una fuente de información que un laboratorio donde experimentar la manipulación de variables o un medio de construcción de conocimiento a través de la interacción social. Tampoco es igual pensar en el ordenador como un instrumento educativo, totalmente incorporado al quehacer cotidiano de profesores y alumnos, que pensar en él como un pasatiempo al margen de la vida escolar (p. 43).

Así las cosas, ha de reconocerse que el rol del maestro, tal como es actualmente concebido, tiende a la extinción. Decir que las nuevas escuelas ya no requieren un cuerpo docente no resulta tan descabellado si nuestro objetivo se resume en enfrentar las nuevas mediaciones contra el modelo tradicional de escolaridad. Más aún, "si las escuelas insisten en las prácticas convencionales obsoletas que definen a la mayoría de las instituciones actuales, alejadas e ignorantes del caudal de vida que desborda a su alrededor, corren el riesgo de convertirse en irrelevantes" (Pérez, 2012, p. 70).

$\mathrm{Si}$, en cambio, aceptamos que un nuevo entramado de relaciones, de seres humanos y de cartografías nos permiten redefinir la labor del maestro, deberemos admitir con Barroso y Cabero (2013) que una escuela para la incertidumbre, el caos y la transformación exige un currículo flexible, innovador y diverso, a fin de que el alumno se forme para la creación y no para la reproducción.

En esta nueva escuela, la comunión entre virtualidades es un imperativo. Esto quiere decir que la única realidad posible en la cual estén inmersos los estu- diantes no puede ser aquella que se dé escuetamente en el aula sin mayor mediación que la palabra hablada. Tal vez no estemos preparados para asumir en la escuela un "aprendizaje de código abierto", en el que el aprendiz define su propio currículo en función de sus intereses y propósitos, mientras va configurando su proyecto personal, social y profesional (Pérez, 2012), pero sí están dadas las condiciones para abrir paso al infinito abanico de posibilidades que ofrece el encuentro entre los contextos en los que se desenvuelve el estudiante y aquellos que brotan de Internet.

Un ejemplo de comunión entre virtualidades lo constituye el proyecto Buenas prácticas con TIC en un taller de cuentos de Correa y Gutiérrez, incluido en el tomo Políticas educativas y buenas prácticas con TIC de Pons, Area, Valverde y Correa (2010), desarrollado en la escuela rural española Ispaster. El fin de este proyecto era recuperar la memoria y las narrativas de las personas mayores de la comunidad para "preservarlos del olvido y del tiempo", a través de la creación de cuentos digitales.

Si tal como mencionamos en el apartado anterior, la virtualidad no reside de forma exclusiva en los entornos digitales sino que reviste los ámbitos artísticos más diversos que permiten al anthropos deambular entre la realidad actual y las realidades potenciales, los relatos Arto Lapurra y Txanton Peperri (títulos dados a las narraciones resultantes de la experiencia pedagógica ya mencionada) son una conjunción entre la historia que constituye el ser actual de una comunidad, la virtualidad pretérita propia del mito o la leyenda -que ocultan sentidos más profundos que aquellos que se pueden percibir sensorialmente- $y$ la recreación, a través de multimedia (imágenes, animaciones, sonidos, etc.), de un relato que abandonará su estatus de potencialidad en cada nuevo encuentro con la memoria colectiva de una comunidad.

Visto lo anterior, no queda duda de que realidad, vir- 
tualidad, literatura y didáctica constituyen conceptos que no solo se asocian dentro del marco narrativo de los libros, sino que su potencial capacidad educativa les permite asociarse $-y$ ya lo han hecho- en escenarios virtuales de comunicación. La narrativa digital es, quizás, el paso más adelantado en este aspecto: las posibilidades que brinda el hipertexto facilitan la participación del receptor en la creación del mensaje; esto es, la intervención del lector en la fase re-creativa de la obra, tal como ocurre en los videojuegos.

No obstante, cabe señalar que, aunque la creación de herramientas digitales demanda inversión tecnológica, económica y profesional especializada, los medios existentes ya en la red pueden propiciar el encuentro antes señalado, tal como ocurre con los Entornos Personales de Aprendizaje (PLE), cuya infraestructura son las redes sociales. Por su medio es posible llevar a cabo múltiples actividades y conexiones que aportan información de forma ágil y sencilla, así como establecer redes de contacto y grupos sociales para desarrollar proyectos tanto académicos como culturales (García, 2013).

\subsection{El ocaso de los saberes}

Aunque el origen de la palabra competencia se remonta al siglo XV y en el contexto educativo a las facultades de Psicología del siglo XVIII, en Lingüística su aparición se relaciona con el culmen de la sexta década del siglo XX y con el estadounidense Noam Chomsky. Dicho término fue ampliado por Hymes (1996) una vez que advirtió cómo

la vida humana parece estar dividida entre la competencia gramatical, una especie de poder ideal derivado innatamente, y la actuación, una exigencia que se asemejaría más bien al morder del fruto prohibido, que arroja al hablante-oyente perfecto a un mundo imperfecto (p. 17).
Caminamos, entonces, hacia la proposición casi centenaria de una concepción educativa adoptada por organismos internacionales y gobiernos nacionales, que aún encuentra impedimentos para permear las instituciones educativas. Ciertamente, dado el caso de la enseñanza de la Lengua, un esquema de saberes basado en la transmisión gramatical y sintáctica resulta más cómodo a la hora de planear, desarrollar y evaluar las realidades de enseñanza-aprendizaje, a pesar de que, tal como lo afirma Hymes (1996), su perfección se conserva hasta que son confrontados con la realidad.

La mediación de la virtualidad facilita una evaluación real de las capacidades comunicativas en determinado idioma (y a pesar de él, cuando la discapacidad lo exige) y el planteamiento de estrategias que propenden por la priorización de la comunicación oral y escrita real y no hipotética. La recurrencia a las herramientas digitales que ofrece un sitio web exige, además, el reconocimiento de competencias comunicativas que no estaban contempladas en la escuela tradicional y que podrían enunciarse en términos de capacidad, de acuerdo con la propuesta de Pérez (2012):

a. Capacidad de utilizar y comunicar de manera disciplinada, crítica y creativa el conocimiento, las herramientas simbólicas que ha ido construyendo la humanidad hasta nuestros días.

b. Capacidad para vivir y convivir democráticamente en grupos humanos cada vez más heterogéneos, en la sociedad global.

c. Capacidad para vivir y actuar de forma autónoma y construir el propio proyecto vital (p. 149).

d. En el continente virtual resulta imposible desarrollar una de estas competencias de forma independiente. La mediación 
digital extiende un abanico de posibilidades para que el docente pase de ser un espectador que revisa saberes a ser el actor de un proceso que exige el desarrollo de habilidades y destrezas. Tal parece que, de igual forma que ocurre con Alicia (de Lewis Carroll), una vez que el aprendiz ha abierto la puerta que lo conduce hacia la realidad virtual recreada en su mente, el retorno a la "realidad" se torna lento y simple.

\subsection{Homo communicans}

La transformación de las prácticas pedagógicas no solo se remite a la evolución de la didáctica sino a las exigencias comunicativas de cada época y lugar. El paso de la comprensión del ser humano como un animal que "sabe que sabe" a un ser de mediaciones que necesita comunicar, implica también una nueva visión del idioma.; esto es: el paso de árboles de palabras entrelazadas mediante reglas prestablecidas a "medios de comunicación" que rompen fronteras entre naciones y que posibilitan una mejor interacción entre comunicantes que comparten y no el mismo código lingüístico.

Reconocida esta realidad, las nuevas tecnologías de la información y la comunicación se constituyen en oportunidad de mejoramiento y no en obstáculo para el fin de toda acción educativa. Aquellos elementos que, aparentemente, hacen las veces de ruido en el acto comunicativo-educativo entre emisor (docente) y receptor (estudiante), se pueden constituir en canal efectivo de comunicación entre agentes educativos. Así las cosas, el que antes era receptor unipersonal pasa a ser emisor-receptor pluripersonal, puesto que se nutre de cientos de mediaciones digitales que incluyen a otros docentes (virtuales o reales); en adición, el papel del receptor pasa a ser el de receptoremisor activo que contribuye tanto en la evolución y replanteamiento del conocimiento como en la adquisición de competencias y en el replanteamiento de las interacciones -cuyo ejemplo más reciente y fehaciente es el surgimiento de una comunicación mediada por emoticonos-.

Aunque aún hay un camino largo por recorrer en este orden, el área de Lengua y Literatura tiene la posibilidad de poner en marcha una serie de mediaciones digitales que podrían influir en la realidad general de las instituciones educativas: una evaluación más eficaz (tanto logística como pedagógicamente hablando) del proceso de aprendizaje lingüístico; una comunicación más fluida e interactiva entre los actores de la educación, que rebasa límites geográficos; una integración de herramientas adecuadas al ritmo de aprendizaje idiomático de cada estudiante; una participación más activa de las familias y de otros involucrados en el proceso de enseñanza-aprendizaje; y un seguimiento de los avances más asequible a los implicados en el aprendizaje y/o conocimiento de una lengua.

\section{NUEVOS HORIZONTES}

Internet es un espacio en el que confluyen relaciones que divagan entre lo real y lo virtual (entre proximidad y lejanía) y en el que múltiples voces se van adecuando a la mutación de los medios. Es, a la vez, medio y espacio geográfico; en otras palabras, se constituye en el elemento primordial para interpretar la sociedad digital y es condición esencial para la gestación de nuevas formas de interacción, incluso pedagógicas.

Esta realidad ha dado lugar a la necesidad del anthropos de ser exclusivamente a través de las mediaciones (panmediación) y ha concedido a los gobiernos la capacidad de moldear mentalidades a través de empalabramientos, iconismos y liturgias (totalismo). Así las cosas, urge que el docente se aparte del estancamiento o la reproducción de esquemas y contenidos y se empeñe en la construcción de 
currículos flexibles, innovadores y diversos, a fin de que sus alumnos se formen -en la era digital- para la creación, a partir de competencias, y no para la reproducción de saberes.

Y puesto que la virtualidad no reside de forma exclusiva en las nuevas tecnologías, sino que alcanza los ámbitos artísticos más diversos que permiten al anthropos deambular entre la realidad actual y las realidades potenciales, el área de Lengua y Literatura cuenta con un saber milenario en su manejo. Realidad, virtualidad, literatura y didáctica de la lengua constituyen conceptos que, asociados en escenarios virtuales de comunicación, pueden propiciar el encuentro de usuarios dispuestos a ejecutar múltiples actividades y conexiones además de establecer redes de contacto y grupos sociales para desarrollar proyectos tanto académicos como culturales.

Debido a este marco de realidad, el horizonte de las herramientas digitales, integradas a los contextos educativos, se amplía para generar espacios de comunión entre virtualidades que involucran a los estudiantes en sus propios procesos de aprendizaje. Mediante los metalenguajes e hipertextos de la web, esta iniciativa ha pasado a ser un gran hipervínculo, a través del cual se integra la comunidad educativa: las familias se suman a los procesos educativos, los estudiantes fortalecen sus competencias para el dominio de un idioma, accediendo a bibliotecas de saberes en contexto, y los maestros enriquecen su experiencia pedagógica hasta convertirla en memoria histórica para los centros educativos.

\section{REFERENCIAS}

Aguaded, J. y Cabero, J. (2013). Tecnologías y medios para la educación en la e-sociedad. Madrid, España: Alianza.

Barroso, J. y Cabero, J. (2013). Nuevos escenarios digitales. Las tecnologías de la información y la comunicación aplicadas a la formación y desarrollo curricular. Madrid, España: Pirámide.

Biblioteca Nacional de Colombia. "Lee lo que quieras, pero lee" es la nueva campaña de la Biblioteca Nacional de Colombia para promover la lectura. Recuperado de http://bibliotecanacional.gov.co.

Biosca, A. (2009). Mil años de virtualidad: origen y evolución de un concepto contemporáneo. Revista de filosofía. Recuperado de http://revistadefilosofia. com.

Borges, J. (2009). Obras Completas. Buenos Aires, Argentina: Emecé.

Bunge, M. (1990). La ciencia, su método y su filosofía. Buenos Aires, Argentina: Siglo XXI.

Castañeda, H. (2011). Navego, luego existo. Medellín, Colombia: Universidad de Antioquia.

Ciofalo, G. y Leonzi, S. (2013). Homo Communicans. Una specie di/in evoluzione. Roma, Italia: Armando Editore.

Cobo, C. y Pardo, H. (2007). Planeta Web 2.0. Inteligencia colectiva o medios fast food. México D.F., México: Flacso y Grup de recerca d'interaccions digitals.

Dahlgren, P. (2012). Paisaje mediático cambiante y participación política. En M. De Moragas (Ed.). La comunicación: de los orígenes a internet (pp. 179-210). Barcelona, España: Gedisa.

De La Cueva, J. (2001, diciembre). El ciberespacio, un nuevo continente que crece explosivamente. Recuperado de http://www.rebelion.org.

Dicasterio para la Pastoral Juvenil Salesiana. (2014). 
La pastoral Juvenil Salesiana. Cuadro de referencia. Roma: S. D. B.

Duch, L. y Chillón, A. (2012). Un ser de mediaciones, antropología de la comunicación. Madrid, España: Herder.

Duch, L. y Chillón, A. (2016). Sociedad mediática y totalismo, antropología de la comunicación. Madrid, España: Herder.

García, A. (2013). Las implicaciones educativas de las redes sociales. En Aguaded, J. y Cabero, J. (Ed.) Tecnologías y medios para la educación en la e-sociedad (pp. 91-116). Madrid, España: Alianza.

Hymes, D. (1996). Acerca de la competencia comunicativa. Forma y función, (9), 13-37. Recuperado de: http://revistas.unal.edu.co.

International Telecommunication Union y United Nations Population Division. (2014, julio). Internet Users. Recuperado de Internet Live Stats (www.InternetLiveStats.com) Elaboration of data by International Telecommunication Union (ITU), World Bank, and United Nations Population Division.

Landeta, A. (Ed.). (2015). Global e-learning. Madrid, España: Universidad a distancia de Madrid.

Malini, F. (2013). A internet e a rua: ciberativismo e mobilização nas redes sociais. Porto Alegre, Brasil: Sulina.

Meeker, M. (2017). Internet trends report. Recuperado de http://www.kpcb.com.

Ministerio de Educación Nacional. (2006). Estándares Básicos de Competencias en Lenguaje, Matemáticas, Ciencias y Ciudadanas. Recuperado de: http:// diae.mineducacion.gov.co.
Monereo, C. y Coll, C. (Eds.). (2008). Psicología de la educación virtual. Madrid, España: Morata.

Monedero, C. (2011). Competencias profesionales en continua mutación. En Ríos, J. y Ruiz, J. (Ed.) Competencias, TIC e innovación (pp. 53-65). Bogotá, Colombia: Ediciones de la U.

Pérez, A. (2012). Educarse en la era digital. Madrid, España: Morata.

Pons, P., Area, M., Valverde, J. y Correa, J. (Eds.). (2010). Políticas educativas y buenas prácticas con TIC. Barcelona, España: Graó.

Sanabria, F. (2011). Querer -creer- vislumbrar lo virtual hoy. En F. Sanabria (Ed.). Vínculos virtuales (pp. 9-28). Bogotá, Colombia. Universidad Nacional.

Spadaro, A. (2012). Cyberteologia. Pensare il cristianesimo al tempo della rete. Milán, Italia: Vita e Pensiero.

Zanoni, L. (2008). El imperio digital. Buenos Aires, Argentina: Ediciones B.

\section{Filmografía}

De Luca, M., Rudin, S. Spacey, K. (productores). Fincher, D. (director). (2010). The Social Network [cinta cinematográfica]. EE. UU. Michael De Luca Productions. Ellison, M., Jonze, S., Landay, V. (productores). Jonze, S. (director). (2013). Her [Cinta cinematográfica]. EE. UU. Annapurna Pictures.

Nolan, C., Thomas, E., Johnson, B., Kosove, A., Cohen, K., Polvino, M., Marter, A, Valdes, D., Ryder, A. (productores). Pfister, W. (director). (2014). Transcendence [Cinta cinematográfica]. EE. UU. Alcon Entertainment. 